\title{
Some specific plausible theoretical aspects to justify and support the existence of thought-carrying particle, thought retaining particle and thought force
}

\author{
Dhananjay Pal \\ Pharmacy College, Bengal School of Technology, Sugandha-Delhi Road, Chuchura, Dist.-Hooghly, West Bengal, INDIA
}

Email address:

dhananjay.pal123@gmail.com,paldhananjay46@yahoo.com

\section{To cite this article:}

Dhananjay Pal. Some Specific Plausible Theoretical Aspects to Justify and Support the Existence of Thought-Carrying Particle, Thought Retaining Particle and Thought Force. American Journal of Physical Chemistry. Vol. 2, No. 5, 2013, pp. 80-93.

doi: $10.11648 /$ j.ajpc.20130205.12

\begin{abstract}
A single field emerged at the origin of the universe, already containing within itself the blueprint of the physical universe. The primordial single field triggered the onset of the universe. Most physicists believe that a single super-force dominated the first instants of creation. Scientists have arrived at a simple but decisive conclusion that consciousness is very much a part of the universe, like other objects. Our consciousness model involving thought-carrying particle (TCP), thought retaining particle (TRP) and thought force $\left(\mathrm{T}_{\mathrm{F}}\right)$ signifies the existence of universal consciousness that exists along with the universe. This universal consciousness is a functional state of the universal mind (UM). This UM is evolved at the Big Bang from void. The UM is constituted by these TCP and TRP in the inherent presence of thought force $\left(\mathrm{T}_{\mathrm{F}}\right)$. Thought force $\left(\mathrm{T}_{\mathrm{F}}\right)$ is an expression of universal consciousness. The Thought force $\left(\mathrm{T}_{\mathrm{F}}\right)$ being the primordial quantum field functions as the original super-force. $\mathrm{T}_{\mathrm{F}}$ being the original super-force functions as the origin of all the fundamental fields. TCP is the carrier of thought force $\left(\mathrm{T}_{\mathrm{F}}\right)$ that, in turn, appears to be the origin of all the fields. The quantized energy $\left(\varepsilon_{T}\right)$ of TCP is responsible to cause the universal consciousness as well as the cosmic microwave background radiation temperature. The individual consciousness owes its origin to the universal consciousness created by the same $\varepsilon_{T}$. The same $\varepsilon_{T}$ is the energy responsible for generating thought force $\left(\mathrm{T}_{\mathrm{F}}\right) . \mathrm{T}_{\mathrm{F}}$ being an expression of the universal consciousness is applicable to any inanimate object as well as to any biological system (having thinking ability). The $\mathrm{T}_{\mathrm{F}}$ exerts its functions both in vitro and in vivo. We showed the existence of thought force in microcosm [TF (micro)] and thought force in macrocosm [TF (macro)]. This TF (micro) is theoretically found to be stronger than the strong nuclear force. TF (macro) is theoretically found to be weaker even than the gravitational force. Any matter as well as any individual mind is constituted by these TCP and TRP that are originated from same Void. Some plausible theoretical scientific aspects have been specified here to justify and support the existence of TCP, TRP and thought force (TF)) along with the TF (micro) and TF (macro). These TCP, TRP and thought force (TF) can provide guidelines to form a possible gross bridge between mind and matter, present physics and cognitive science, psychology and natural sciences, classical physics and quantum physics.
\end{abstract}

Keywords: Void, Universal Mind (UM), Thought Force $\left(\mathrm{T}_{\mathrm{F}}\right)$, Though-Carrying Particles (TCP), Thought Retaining Particles (TRP), Quantized Energy $\left(\in_{\mathrm{T}}\right.$ ) of TCP, Universe Wide Web (UWW), Cosmic Microwave Background Radiation (CMBR)

\section{Introduction}

In Eastern philosophical traditions, consciousness is intrinsic to the universe, whereas in most Western views, consciousness is extrinsic, emerging from complex computation. How can these views be reconciled?

It is most relevant and important to indicate the names of various eminent physicists like Erwin Schrödinger, Eugene Wigner, Brian Josephson, John Wheeler, Roger Penrose, Henry P Stapp, Freeman J. Dyson, Paul Davies, David Bohm, Basil Hiley, Fritjof Capra, Fred Alan Wolf and Amit Goswami who have addressed the inclusion of consciousness in their work. Consciousness is to be taken into account.

1.1. In contrast to the usual linear sequence of matter, 
body, life, brain, mind, consciousness, here the proposed cyclic sequence is first universal consciousness (a functional state of the universal mind), and then matter, body, life, brain, and regeneration of mind and consciousness. The evolution of life with mind and consciousness is possible purely due to the inherent existence of universal consciousness which exists along with the universe. The human nervous system is evolved to provide an appropriate material structure to individualize the universal consciousness, a characteristic of reality, pervading all manifestations.

Consciousness model of Pal et al [1-3] involving TCP, TRP and thought force $\left(T_{F}\right)$ signifies the existence of universal consciousness that exists along with the universe. Pal et al [3] showed that this universal consciousness is a functional state of Universal Mind (UM). Pal et al [3] explained that the UM is evolved at the Big Bang from the eternal Void. This Void, in turn, is the source of infinite energy. And this UM is a finer matter. The individual mind being a constituent of the UM is also a finer matter. The constituents of the UM and individual mind are the same. The ultimate constituents of matter and mind are the same as both mind and matter are aspects of one fundamental reality, which is called UM. The brain is the mediating link or interface between the individual mind and body.

Pal et al [3] explained that the constituents of the UM are the ultimate constituents of matter itself as everything in this universe is a manifestation of this UM. Pal et al [3] expressed that the UM is constituted by these TCP and TRP in the inherent presence of thought force $\left(\mathrm{T}_{\mathrm{F}}\right)$. Pal et al $[1,3]$ further explained that the ultimate constituents of matter and mind are these TCP and TRP in the inherent presence of thought force $\left(\mathrm{T}_{\mathrm{F}}\right)$ in vitro and thought force $\left(\mathrm{T}_{\mathrm{F}}\right)$ in vivo [See Scheme-I]. It is to be noted that these TCP and TRP are the ultimate constituents of any matter in the inherent presence of thought force $\left(\mathrm{T}_{\mathrm{F}}\right)$ in vitro. And these TCP and TRP are the ultimate constituents of any mind in the inherent presence of thought force $\left(\mathrm{T}_{\mathrm{F}}\right)$ in vivo.

Pal et al [1,3] further explained that the existence of universal consciousness is the primary cause for the evolution of life. Without the inherent existence of universal consciousness, the inanimate matter itself cannot generate life and consciousness. These TCP and TRP, the constituents of the UM and the ultimate constituents of matter and mind are conceived here to be originated from the Void at the Big Bang to evolve the space-time continuum and the UM along with the universal consciousness. Thought force $\left(\mathrm{T}_{\mathrm{F}}\right)$, an expression of this universal consciousness, is thus the primordial quantum field and it exerts its functions both in vitro and in vivo.

\subsection{General View for the Evolution of the Universe}

Big Bang $\rightarrow$ Universe $\rightarrow$ [Fields + Particles \& Antiparticles + STC $] \rightarrow[$ Matter and Fields + STC $] \rightarrow$ Matter and Fields + STC + Life as well as consciousness.
If the universe exists along with the universal consciousness that, in turn, is a functional state of the universal mind (UM) and if this UM is evolved at the Big Bang from the eternal void, then

Our view for the evolution of the universe (see Scheme-I)

VOID $\rightarrow$ [Big Bang $] \rightarrow[$ TCP, TRP \& Anti-TRP in the inherent presence of thought force $\left.\left(\mathrm{T}_{\mathrm{F}}\right)+\mathrm{STC}\right] \rightarrow$ [Universal Mind with universal consciousness + TCP \& TRP in the inherent presence of thought force $\left(\mathrm{T}_{\mathrm{F}}\right)+\mathrm{STC}+$ $\mathrm{UTF}$ ] $\rightarrow$ [Universal Mind with universal consciousness + Matter and Fields \{including thought force $\left.\left(\mathrm{T}_{\mathrm{F}}\right)\right\}+$ TCP \& $\mathrm{TRP}+\mathrm{STC}+\mathrm{UTF}] \rightarrow$ Universal Mind with universal consciousness + Matter and Fields including thought force $\left.\left(\mathrm{T}_{\mathrm{F}}\right)\right\}+$ Life as well as consciousness $+\mathrm{TCP} \& \mathrm{TRP}+\mathrm{STC}$ + UTF [where thought force $\left(\mathrm{T}_{\mathrm{F}}\right)$ is the origin of all the fields, TCP (Though-carrying particle) is the origin of all the field particles, TRP (Thought retaining particle) is the origin of all the matter particles, anti-TRP is the origin of all the anti-particles, STC $=$ Space time continuum and $\mathrm{UTF}=$ Universal thought frequency $\cong$ frequency of the TCP].

Physicists determined that underlying quantum fields give birth to elementary particles. Bhaumik [4] mentioned that Frank Wilczek pointed out, "In quantum field theory, the primary elements of reality are not individual particles, but underlying fields. Thus, for example, all electrons are but excitations of an underlying field, naturally called electric field". The same holds true for all the fundamental particles of which matter is made.

The existence of matter depends on the existence of force and vice versa. TCP cannot exist without TRP and vice versa. Many physicists believe that unifying all the forces, including gravity, into a single theory would require a phenomenon called super-symmetry. With supersymmetry, every fermion would have a boson twin, and vice-versa. The thought force $\left(\mathrm{T}_{\mathrm{F}}\right)$ is carried by the TCP in the presence of its super-symmetrical partner TRP. TCP that behaves like boson should accompany its supersymmetrical partner TRP that functions like fermion in the generalized simpler way. It is to be noted that these TCP and TRP function like wavicle: wave-particle duality.

\section{Thought Force}

Pal et al [1, 3] and Pal [5] explained the existence of thought force $\left(\mathrm{T}_{\mathrm{F}}\right)$. Thought force $\left(\mathrm{T}_{\mathrm{F}}\right)$, an expression of the universal consciousness, is the primordial quantum field that, in turn, functions as the primary unified field. This $T_{F}$ being an expression of the universal consciousness is applicable to any inanimate object as well as to any biological system (having thinking ability). Thus the $\mathrm{T}_{\mathrm{F}}$ being an expression of the universal consciousness exerts its functions both in vitro and in vivo (see Scheme-I and Scheme-II). 


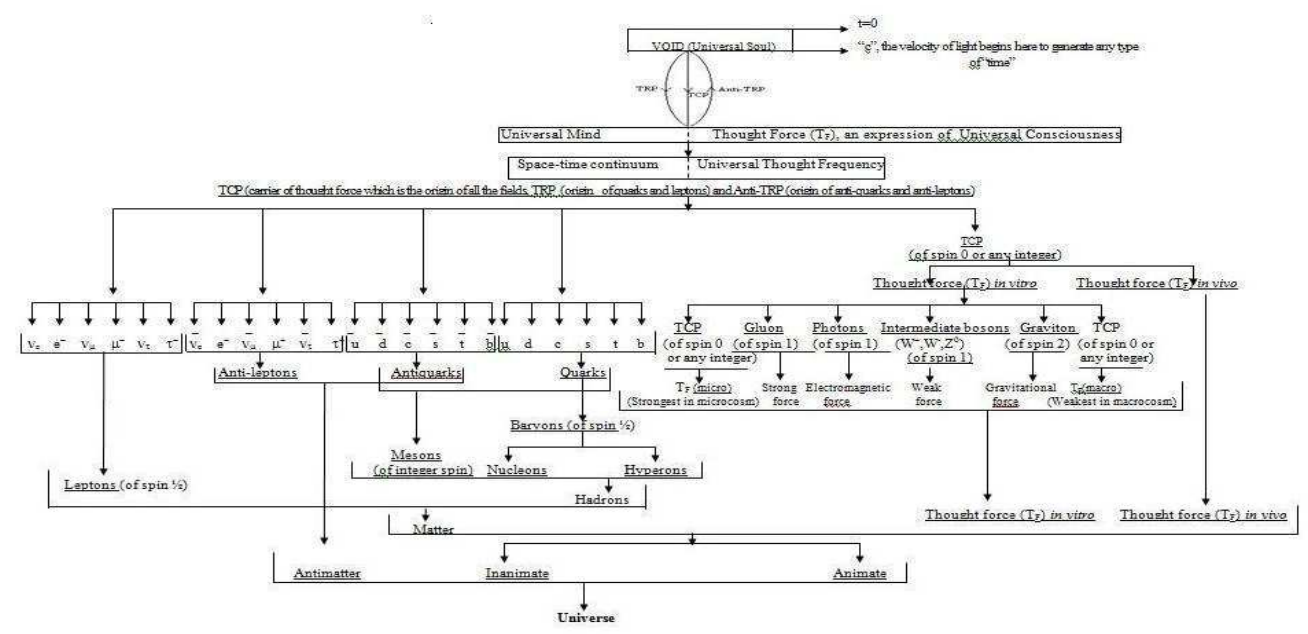

Scheme-I: Schematic representation showing the evolution of the universe from the void incorporating the postulated TCP (Thought carrying particle), TRP(Thought retaining particle), and thought force $\left(T_{F}\right)$. Laws of absolute conservation of mass, charge (and color) are to be maintained in order to develop a general theory for the unification of physics which would be freely applicable to the more general situations involving the non-living system and living system having consciousness. Here TCP is the carrier of the thought force ( $T_{F}$ ) that , in turn, is the origin of all the fields. TRP is the origin of all the matter particles. It is to be noted that these TCP and TRP function like wavicle: wave-particle duality. Here thought force $\left(T_{F}\right)$ is an expression of the "universal consciousness".

Thought force ( $\mathbf{T}_{\boldsymbol{F}}$ ) [is a single super-force that dominated the first instants of creation and it is the primordial quantum field
[The thought force $\left(\mathrm{T}_{F}\right)$ is carried by the TCP (thought-carrying particle) in the presence of its super-symmetrical partner TRP (thought retaining particle)]

$\downarrow$

Thought force $\left(\mathrm{T}_{\mathrm{P}}\right)$ in vitro

[The non-living system of the world is governed by the thought force $\left(\mathrm{T}_{\mathrm{F}}\right)$ in vitro]

[The non-living system of the world is governed by the thou
$T_{p}$ (micro), SNF, EMF, WNF, GF and $T_{F}$ (macro)

where $T_{F}($ micro $)=$ Thought force in microcosm, $\mathrm{SNF}=$ Strong nuclear force, $\mathrm{EMF}=$ Electromagnetic force, $\mathrm{WNF}=$ Weak nuclear force, $\mathrm{GF}=$ Gravitational force and $\mathrm{T}_{F}($ macro $)=$ Thought force in macrocosm. It is expressed here that $\mathrm{T}_{\mathrm{F}}$ (micro) is a stronger force than the SNF and $T_{P}($ macro) is a weaker force even than the GF.
Thought force $\left(\mathrm{T}_{\mathrm{F}}\right)$ in vivo [The living system of the world is governed by the thought force $\left(\mathrm{T}_{F}\right)$ in vivo]
Scheme-II: Thought force and its significant roles: Most physicists believe that a single super-force dominated the first instants of creation. This mysterious super-force is the postulated Thought force $\left(\mathrm{T}_{F}\right)$. It is possible that the evolution of all the fundamental fields is originated from this super-force that is the Thought force $\left(\mathrm{T}_{\mathrm{r}}\right)$ in our view. This thought force $\left(\mathrm{T}_{\mathrm{P}}\right)$ is carried by the TCP (thought-carrying particle) in the presence of its super-symmetrical partner TRP (thought retaining particle). TCP is the carrier of thought force $\left(\mathrm{T}_{\mathrm{F}}\right)$ that, in turn, is the origin of all the fields. TCP is the origin of all the field particles. TRP is the origin of all the matter particles. TCP cannot exist without TRP and vice versa. Our consciousness model involving TCP, TRP and thought force $\left(T_{F}\right)$ signifies the existence of universal consciousness that exists along with the universe. We showed that the quantized energy $\left(\epsilon_{T}\right)$ of the TCP is responsible to cause the universal consciousness as well as the cosmic microwave background radiation temperature. The individual consciousness owes its origin to the universal consciousness created by the same $\varepsilon_{T}$. The same $\varepsilon_{T}$ is the energy responsible for generating Thought force $\left(T_{F}\right)$. Thus, Thought force $\left(T_{F}\right)$ is an expression of the universal consciousness. Thought force ( $\mathrm{T}_{\boldsymbol{V}}$ ) being an expression of the universal consciousness is applicable to any inanimate object as well as to any biological system (having thinking ability). The Thought force $\left(\mathrm{T}_{\mathrm{F}}\right)$ exerts its functions both in vitro and in vivo. The non-living system of the world is governed by the thought force $\left(\mathrm{T}_{\mathrm{F}}\right)$ in vitro and this Thought force $\left(\mathrm{T}_{F}\right)$ in vitro gives rise to $\mathrm{T}_{\mathrm{F}}($ micro), SNF, EMF, WNF, GF and $T_{p}$ (macro) where $T_{r}$ (micro) $=$ Thought force in microcosm, SNF $=$ Strong nuclear force, $\mathrm{EMF}=$ Electromagnetic force, $\mathrm{WNF}=$ Weak nuclear force, $\mathrm{GF}=$ Gravitational force and $\mathrm{T}_{\mathrm{F}}$ (macro) $=$ Thought force in macrocosm. It is to be noted here that $\mathrm{T}_{p}$ (micro) is a stronger force than the $\mathrm{SNF}$ and $\mathrm{T}_{\mathrm{F}}$ (macro) is a weaker force even than the GF. The living system of the world is governed by the thought force $\left(T_{F}\right)$ in vivo and this Thought force $\left(T_{F}\right)$ in vivo is a type of force that represents the biological 'thought' which is the action of mind. This 'thought' being a type of force controls the 'thought processes' involving the firing of neurons through the quantum mechanical activities of these postulated TCP and TRP in the presence of consciousness. This consciousness, in turn, is the quantized energy $\left(\varepsilon_{r}\right)$ of the TCP. Thought force $\left(\mathrm{T}_{F}\right)$ being the primordial quantum field functions as the original single primary unified field that is not only the origin of all the four fundamental fields along with both the $T_{V}$ (micro) and $T_{F}$ (macro) but also the origin of Thought force $\left(\mathrm{T}_{\mathrm{F}}\right)$ in vivo.

Note: What was previously called a force is now usually called a field or interaction. The existence of matter depends on the existence of force and vice versa. Matter particles are usually designated as "Fermions", because they follow Fermi-Dirac Statistics. Matter particles obey Pauli's exclusion principle; they are of spin 1/2. Force particles are usually designated as "Bosons", because they follow Bose-Einstein Statistics. Force particles do not obey Pauli's exclusion principle; they are of spin o, or any integer like 1, 2,3 etc. TCP cannot exist without TRP and vice versa. Many physicists believe that unifying all the forces, including gravity, into a single theory would require a phenomenon called super-symmetry. With super-symmetry, every fermion would have a boson twin, and vice-versa. TCP that behaves like boson should accompany its super-symmetrical partner TRP that functions like fermion in the generalized simpler way. 
Physicists determined that underlying quantum fields give birth to elementary particles. Pal [5] expressed that the thought force $\left(T_{F}\right)$ is the primordial quantum field. Thought force $\left(\mathrm{T}_{\mathrm{F}}\right)$ being the primordial quantum field functions as the primary unified field. Thought force $\left(\mathrm{T}_{\mathrm{F}}\right)$ being the primordial quantum field gives birth to TRP that appears to be the origin of all the matter particles. TCP is the carrier of thought force $\left(\mathrm{T}_{\mathrm{F}}\right)$ that, in turn, appears to be the origin of all the fields. TCP thus appears to be the origin of all the field particles.

In a purpose to involve both the non-living and living systems of the world, Pal [5] has shown the existences of these TCP, TRP and thought force $\left(\mathrm{T}_{\mathrm{F}}\right)$ in vitro and thought force $\left(\mathrm{T}_{\mathrm{F}}\right)$ in vivo. Anyone can call this TCP by any other name, but as the highly developed living system will have to be evolved in the universe in the long run and as the thought of highly developed living system appears to be a kind of force to be called the thought force $\left(\mathrm{T}_{\mathrm{F}}\right)$ in vivo, we considered it is wise to call it as TCP. Further, as the universe exists along with the universal consciousness that, in turn, is created by the quantized energy $\left(\varepsilon_{T}\right)$ of TCP, we had to use the term TCP.

Pal (5) expressed that the non-living system of the world is governed by the thought force $\left(\mathrm{T}_{\mathrm{F}}\right)$ in vitro and this Thought force $\left(\mathrm{T}_{\mathrm{F}}\right)$ in vitro gives rise to $\mathrm{T}_{\mathrm{F}}$ (micro), $\mathrm{SNF}$, EMF, WNF, GF and $\mathrm{T}_{\mathrm{F}}$ (macro) where $\mathrm{T}_{\mathrm{F}}$ (micro) $=$ Thought force in microcosm, $\mathrm{SNF}=$ Strong nuclear force, $\mathrm{EMF}=$ Electromagnetic force, $\mathrm{WNF}=$ Weak nuclear force, $\mathrm{GF}=$ Gravitational force and $\mathrm{T}_{\mathrm{F}}$ (macro) $=$ Thought force in macrocosm. It is to be noted here that $\mathrm{T}_{\mathrm{F}}$ (micro) is a stronger force than the $\mathrm{SNF}$ and $\mathrm{T}_{\mathrm{F}}$ (macro) is a weaker force even than the GF.

Pal (5) also expressed that the living system of the world is governed by the thought force $\left(\mathrm{T}_{\mathrm{F}}\right)$ in vivo and this Thought force $\left(\mathrm{T}_{\mathrm{F}}\right)$ in vivo is a type of force that represents the biological 'thought' which is the action of mind. This 'thought' being a type of force controls the 'thought processes' involving the firing of neurons through the quantum mechanical activities of these TCP and TRP in the presence of consciousness. Consciousness in living organisms is a process which involves the quantum mechanical activities of these TCP and TRP, the ultimate constituents of any matter as well as any mind in the inherent presence of thought force $\left(\mathrm{T}_{\mathrm{F}}\right)$ in vitro and the thought force $\left(\mathrm{T}_{\mathrm{F}}\right)$ in vivo as indicated by Pal [3]. These TCP and TRP govern the activities of neurons (not the other way round). Neurons are simply the equipments used to generate consciousness and awareness. This consciousness, in turn, is the quantized energy $\left(\varepsilon_{T}\right)$ of TCP. The thought force $\left(\mathrm{T}_{\mathrm{F}}\right)$ in vivo is demonstrated in numerous experiments in which thought has an effect on a physical process (often known as mind over matter). This biological 'thought' is a type of force that can cause movement. Controlling movement through thought alone is observed in several experiments conducted by many scientists as indicated by Pal (5). These experiments thus signify the existence of thought force $\left(\mathrm{T}_{\mathrm{F}}\right)$ in vivo.

Pal [5] explained the existence of $\mathrm{T}_{\mathrm{F}}$ (micro) $(=$ Thought force in microcosm). This $\mathrm{T}_{\mathrm{F}}$ (micro) is the strongest interaction (a new class of 'extra strong' interaction). It is stronger than SNF (Strong Nuclear Force).

Pal [5] has also shown the existence of $\mathrm{T}_{\mathrm{F}}$ (macro) (= Thought force in macrocosm). It is the "weakest force" which is much weaker even than the gravity.

2.1. Pal et al [3] expressed that the CMBR temperature is due to $\varepsilon_{T}$, the quantized energy of TCP where $\varepsilon_{T}=4.384 \times 10^{-16} \mathrm{erg} \equiv 2.73^{\mathrm{O}} \mathrm{K}$ that is very close to $2.725^{\circ} \mathrm{K}$ (CMBR temperature). As per Pal et al [3], it is interesting to note that all of the three different equations ultimately give rise to the same result that is equivalent to the CMBR temperature. A sort of relationship is thus observed between the $\varepsilon_{T}$ and the CMBR temperature. This coincidence is thus signifying a probable role of TCP on the maintenance of CMBR temperature. Further, this coincidence is also signifying the existence of these TCP in the presence of TRP. TCP cannot exist without TRP and vice versa. The presence of TCP, TRP and Thought force $\left(\mathrm{T}_{\mathrm{F}}\right)$ in the universe is thus indicated and expressed mathematically. At present we are unable to explain when and how these TCP and TRP decoupled from the primordial cosmic soup.

Pal et al $[1,3]$ showed that the quantized energy $\left(\varepsilon_{T}\right)$ of TCP is responsible to cause the universal consciousness as well as the cosmic microwave background radiation temperature. The individual consciousness owes its origin to the universal consciousness created by the same $\varepsilon_{T}$.

Ultimately this $\mathcal{E}_{T}$ represents universal consciousness. The existence of CMBR temperature indicates the existence of the TCP in the presence of TRP. The existence of TCP ensures the existence of the thought force $\left(\mathrm{T}_{\mathrm{F}}\right)$. Further, this $\mathrm{T}_{\mathrm{F}}$ being an expression of the quantized energy $\left(\boldsymbol{\varepsilon}_{T}\right)$ of TCP exerts its functions both in vitro and in vivo.

2.2. Pal et al [3] developed three different equations expressing the quantized energy ( $\boldsymbol{\varepsilon}_{T}$ ) of TCP. The value of $\mathcal{E}_{T}$ in one of the three equations is shown below:

$$
\varepsilon_{T}=4.384 \times 10^{-16} \mathrm{erg} \equiv 2.73 \times 10^{-4} \mathrm{eV} \equiv 2.73^{0} \mathrm{~K} \cong C M B R \text { temperature } \equiv 2.725^{\circ} \mathrm{K}
$$

It is to be noted that $1 \mathrm{erg} \cong 0.6241807 \times 10^{12} \mathrm{eV}$ and $10^{-4} \mathrm{eV} \cong 1^{0} \mathrm{~K}$ (where $\mathrm{K}=$ Kelvin) as indicated by Weisskopf [6]. 


\section{Some Specific Plausible Theoretical} Aspects to Justify and Support the Existence of TCP, TRP, thought Force $\left(T_{F}\right)$, thought Force $\left(T_{F}\right)$ in Vitro and thought Force $\left(\mathrm{T}_{\mathrm{F}}\right)$ in Vivo along with $T_{F}$ (Micro) and $T_{F}$ (Macro)

(i) The Universal Temperature Corresponding to the CMBR Temperature Indicates the Existence of the Quantum Mechanical Activities of these TCP in the Inherent Presence of TRP

Cosmic Background Explorer (COBE) successfully found that the CMBR has a perfect black body nature with a temperature of $2.725^{\circ} \mathrm{K}$. Pal et al [3] expressed that the CMBR temperature is due to $\mathcal{E}_{T}$, the quantized energy of TCP where $\varepsilon_{T}=4.384 \times 10^{-16} \mathrm{erg} \equiv 2.73^{0} \mathrm{~K}$ that is very close to $2.725^{\circ} \mathrm{K}$ (CMBR temperature). Currently the best CMBR temperature is determined to be $2.7255 \pm 0.0006$ Kelvin as indicated by Fixsen [7]. A sort of relationship is thus observed between the $\mathcal{E}_{T}$ and the CMBR temperature, thereby indicating the existence of TCP in the inherent presence of TRP.

Pal et al [3] explained that the universe exists along with the universal consciousness that, in turn, is created by the quantized energy $\left(\varepsilon_{T}\right)$ of TCP. This $\varepsilon_{T}$ of the TCP exists along with the universe to cause the universal consciousness as well as the CMBR temperature.

Pal et al [3] explained that these TCP, TRP and Thought force $\left(T_{F}\right)$ had played their significant roles at the onset of the universe and they exist till today in this universe. For this reason, Pal et al $[1,3]$ wanted to find out any possible relationship between the CMBR temperature and the quantized energy $\left(\varepsilon_{T}\right)$ of TCP. Pal et al [3] expressed that the CMBR temperature is due to $\varepsilon_{T}$, the quantized energy of TCP where $\varepsilon_{T}=4.384 \times 10^{-16} \mathrm{erg} \equiv 2.73^{\circ} \mathrm{K}$ that is very close to $2.725^{\circ} \mathrm{K}$ (CMBR temperature). Three different equations expressing the quantized energy $\left(\mathcal{E}_{T}\right)$ of TCP have been shown and it is interesting to note that all of the three different equations ultimately give rise to the same result that is equivalent to the CMBR temperature. A sort of relationship is thus observed between $\varepsilon_{T}$ and the CMBR temperature. This coincidence thus signifies a probable role of TCP on the maintenance of CMBR temperature. Further, this coincidence also signifies the existence of these TCP in the presence of TRP. TCP cannot exist without TRP and vice versa. The presence of TCP, TRP and Thought force $\left(\mathrm{T}_{\mathrm{F}}\right)$ in the universe is thus indicated and expressed mathematically. At present we are unable to explain when and how these TCP and TRP decoupled from the primordial cosmic soup. (ii) The Anisotropy of CMBR Indicates the Existence of Quantum Mechanical Activities of these TCP in the Presence of TRP

According to the Big Bang theory, CMBR should show the characteristics of a thermal black body spectrum. George F. Smoot and John C. Mather were awarded the 2006 Nobel Prize in Physics for their discovery of the black body form and anisotropy of the CMBR. The detection of fluctuations in the CMBR signifies that galaxies and clusters of galaxies grew from very small seed fluctuations in the early universe through gravitational aggregation. These tiny deviations (anisotropy) have been attributed to the first structures to form in the Universe. The existence of anisotropy of the CMBR, in our view, is possible due to the quantum mechanical activities of these TCP in the presence of TRP. TCP cannot exist without TRP and vice versa. It is to be noted that these TCP and TRP function like wavicle: wave-particle duality.

\section{(iii) Quantum Fields Signify the Existence of $T_{F}$ (Micro) and $T_{F}$ (Macro)}

Pal (5) expressed that Thought force $\left(\mathrm{T}_{\mathrm{F}}\right)$ is bridging the microcosm and macrocosm through the generation of a universal web of quantum fields of $T_{F}$ (micro) and $T_{F}$ (macro).

Wilczek [8] expressed that intangible quantum fields fill everything in the universe, including the voids inside atoms and the universe, space between galaxies. Quantum electrodynamics has shown that even the vacuum of space, utterly devoid of matter or conventional forms of energy, actually seethes with activity. The possibility of existence of a universal web of quantum fields signifies the existence of $\mathrm{T}_{\mathrm{F}}$ (micro) and $\mathrm{T}_{\mathrm{F}}$ (macro) due to the existence of the quantum mechanical activities of these TCP in the presence of TRP.

(iv) David Bohm's “Wholeness and Implicate Order" Indicates the Existence of TCP, TRP, thought Force $\left(T_{F}\right)$ in vitro and thought Force $\left(T_{F}\right)$ in Vivo along with $T_{F}$ (Micro) and $T_{F}$ (Macro)

Quantum physics has discovered a seamless fabric of intertwining threads of energy. We live in an unimaginable ocean of waves and frequencies of TCP and TRP. David Bohm calls this the "Implicate Order" that is maintained through the quantum mechanical activities of these TCP and TRP in the presence of thought force $\left(\mathrm{T}_{\mathrm{F}}\right)$ in vitro and thought force $\left(\mathrm{T}_{\mathrm{F}}\right)$ in vivo along with $\mathrm{T}_{\mathrm{F}}$ (micro) and $\mathrm{T}_{\mathrm{F}}$ (macro).

\section{(v) Global Consciousness Project (Nelson, 2009) Indicates the Existence of TCP, TRP, TF (micro), TF (Macro) and thought Force (TF) in Vitro and thought Force (TF) in Vivo}

Nelson [9], Director of Global Consciousness Project, has observed through the experimentation that coherent consciousness creates order in the world; and subtle interactions link us with each other and the Earth. When 
human consciousness becomes coherent and synchronized, the behavior of random systems may change. Quantum event based random number generators (RNGs) produce completely unpredictable sequences of zeroes and ones. But when a great event synchronizes the feelings of millions of people, our network of RNGs becomes subtly structured. The probability is less than one in a billion that the effect is due to chance. The evidence suggests an emerging noosphere, or the unifying field of consciousness described by sages in all cultures. This evidence signifies and proves the existence of universal consciousness. Pal et al [3] expressed that this universal consciousness functions as a universe wide web (uww) covering the universe as a whole with all its parameters (including void) and inhabitants (with or without consciousness). Pal et al [3] have also expressed and shown the existence of these TCP, TRP and thought force (TF) in vitro and thought force (TF) in vivo. Global Consciousness Project of Nelson [9] indicates the existence of TCP, TRP, TF (micro), TF (macro) and thought force (TF) in vitro and thought force (TF) in vivo.

(vi) The Existence of Universal Consciousness Indicates the Existence of TCP, TRP, thought Force (TF) in Vitro and thought Force (TF) in Vivo along with the TF (Micro) and TF (Macro)

The existence of universal consciousness is explained by Radin [10] through experimentation as it is expressed in his book The Conscious Universe: The Scientific Truth of Psychic Phenomena. Further, Consciousness, not matter, is the ground of all existence, declares University of Oregon physicist Goswami through his published (1993) book, "The Self-Aware Universe: How Consciousness Creates the Material World".

As per Penrose [11], consciousness is a part of the universe. Van De Bogart [12] explained, "Since consciousness is a part of the universe it then follows that all consciousness, and the universe, are of the same matrix of energy fields". Our consciousness model involving TCP, TRP and thought force $\left(\mathrm{T}_{\mathrm{F}}\right)$ signifies the existence of universal consciousness that, in turn, exists along with the universe.

Pal et al [3] showed that the quantized energy $\left(\varepsilon_{T}\right)$ of TCP is responsible to cause the universal consciousness as well as the cosmic microwave background radiation temperature. The individual consciousness owes its origin to the universal consciousness created by the same $\varepsilon_{T}$. The same $\varepsilon_{T}$ is the energy responsible for generating thought force $\left(\mathrm{T}_{\mathrm{F}}\right)$. It is to be noted that this $\mathrm{T}_{\mathrm{F}}$ exerts its functions both in vitro and in vivo (see Scheme-II). Ultimately this

$\boldsymbol{\varepsilon}_{T}$ represents universal consciousness.

Many physicists agree with the idea that consciousness is non-local and fundamental in the universe. Scientists have arrived at a simple but decisive conclusion that consciousness is very much a part of the universe, like other objects, and therefore bound to obey mathematical laws. They are waiting to acquire the right kind of mathematical tools and operational technicalities to explain the laws of consciousness.

\section{(vii). The Constant Emission of Microwaves by Living beings Including Human being Indicates the Existence of the Quantum Mechanical Activities of these TCP and TRP}

Pal et al [3] expressed that consciousness appears to be a type of 'mental light'. Although it is assumed that these postulated TCP and TRP exist in the universe to behave, in general, like photons or bio-photons for causing the universal consciousness as well as the Cosmic microwave background radiation (CMBR) temperature, yet they may be mathematically allotted a mass $\left(\mathrm{m}_{\mathrm{T}}\right)$ equivalent to $4.831 \times 10^{-37} \mathrm{~g}$ to $5.5 \times 10^{-37} \mathrm{~g}$.

It has been experimentally observed in the field of "biophotonics" [13-15] that living beings including human being emit microwaves constantly and regularly in a particular pattern which may be responsible for maintaining not only the 'metabolism' along with 'consciousness' but also for maintaining the universal existence. This microwave radiation, in our view, is due to the emission of a type of photons usually called "biophotons" which are nothing but these TCP and TRP as these TCP and TRP behave like biophotons in animals and like simple photons in inanimate objects indicated by Pal et al [1].

Pal et al $[1,3]$ have shown by calculation that the biological systems would have to emit microwaves having

of the order of $0.4 \mathrm{~cm} \cong 10^{-4} \mathrm{eV} \cong 10^{-16} \mathrm{erg} \cong \epsilon_{\mathrm{T}}$, the quantized energy of TCP radiated by the radiant mass of this universe.

What are the degrees of freedom of a TCP? As a TCP behaves like a photon/biophoton, its degrees of freedom should be same as the degrees of freedom of a photon.

\section{(viii). Infraquarks, Infra-Electrons Indicated by}

Weisskopf [6], Bremsstrahlung and Inverse Photo-

Electric Effect Indicated by Wehr [16] Signify the

Existence of TCP and TRP in the Presence of TF (Micro)

We now know that quarks, leptons and other elementary particles are nothing but discrete packets of energy. Any elementary particle is nothing but the quantized "lumps of energy". Although objects appear as solid, their constituent parts are in a constant state of flux.

Depending on the conditional elementarity of particles, quarks and electrons at sufficiently high temperatures are thought to be constituted by "infraquarks" or "infraelectrons" indicated by Weisskopf [6]. It is possible that these 'infraquarks' or 'infraelectrons' are ultimately constituted by these TCP and TRP in the presence of $T_{F}$ (micro). In other words, all the quarks, leptons and other elementary particles are ultimately constituted by these TCP and TRP in the presence of $\mathrm{T}_{\mathrm{F}}$ (micro).

Modern experiments have probed at length scales of about $10^{-17} \mathrm{~cm}$, but even at that scale there is nothing to indicate that the electron has any structure. Although, Maris [17] claims that electrons can also be split into fragments 
called 'electrinos' which are conceived to be constituted by these TCP and TRP in the presence of $\mathrm{T}_{\mathrm{F}}$ (micro). Wehr [16] mentioned, "We have pointed out that radiation results when a charged body is accelerated. Therefore when an electron loses a large amount of energy by being decelerated, an energetic pulse of electromagnetic radiation is produced. This is an inverse photoelectric effect in which an electron produces a photon. This photon, in our view, is the liberated TCP and TRP with which an electron is assumed to be constituted in the presence of $\mathrm{T}_{\mathrm{F}}$ (micro). What is called "bremsstrahlung" indicated by Wehr [16] indicating the breaking of charged particles like electrons signifies "breaking radiation" in which an electron produces a photon. This photon is nothing but the liberated TCP and TRP with which an electron is assumed to be composed in the presence of $\mathrm{T}_{\mathrm{F}}$ (micro).

According to the present nuclear theory, all three types of pi-mesons are found in the nucleus, and it is believed that both protons and neutrons are continuously emitting or absorbing positive, negative and neutral pi-mesons indicated by Wehr [16]. Each nucleon thus has an associated meson field through which it interacts with other nucleons. The pions play the same role in the meson field as photons do in an electromagnetic field. In our proposition, TCP itself may play the similar role within a nucleon itself (at a region of $10^{-18} \mathrm{~cm}$, the calculated radius of a TCP or TRP within a nucleon) in the $\mathrm{T}_{\mathrm{F}}$ (micro) field.

\section{(ix) Possible Bridge between the Classical Physics and Quantum Physics through Consciousness $\left(=\mathcal{E}_{T}=\right.$ Quantized Energy of the TCP) Indicates the Existence of TCP and TRP}

Pal [18] explained the formation of a possible gross bridge between the classical physics and quantum physics through consciousness $\left(=\mathcal{E}_{T}=\right.$ quantized energy of the TCP) thus indicating the existence of TCP and TRP.

\section{(x) TCP and TRP Play the Significant Roles in the So- Called 'Non-Locality' Problem in Quantum Mechanics:}

Everything in this universe is interconnected. The entire Universe or the particles in it are 'connected' through the existence of the quantum mechanical activities of these TCP in the presence of TRP. Pal et al [3] showed that the quantized energy $\left(\varepsilon_{T}\right)$ of TCP is responsible to cause the universal consciousness as well as the cosmic microwave background radiation temperature. The individual consciousness owes its origin to the universal consciousness created by the same $\varepsilon_{T}$. This universal consciousness functions as a universe wide web (uww) covering the universe as a whole with all its parameters (including void) and inhabitants (with or without consciousness). In this picture, uww of consciousness, quantum concepts like wave particle dualism, position momentum uncertainty, nonlocality and concept of unified field become somewhat understandable as all the entities of this universe are interlinked and intertwined. In this picture, the universal consciousness replaces ether of yesteryears and contains the whole of the universe in its fold.

The 'spooky action-at-a-distance' is thus built in nature through the existence of the quantum mechanical activities of these TCP in the inherent presence of TRP. The spooky non-local correlations-at-a-distance might evidence a Holy Ghost at work through the existence of the quantum mechanical activities of these TCP and TRP in the inherent presence of Thought force $\left(\mathrm{T}_{\mathrm{F}}\right)$ in vitro and Thought force $\left(\mathrm{T}_{\mathrm{F}}\right)$ in vivo.

It is possible that the quantum enigma can be tackled by accepting the existence of the quantum mechanical activities of these TCP and TRP that are the ultimate constituents of any matter as well as the individual mind, the functional state of which, in turn, generates 'consciousness'. This 'consciousness' is acting as an interlinking agent between the animate and inanimate.

\section{(xi) TCP and TRP Play Significant Roles in the Quantum Measurement}

Pal et al [3] explained that consciousness is the quantized energy $\left(\varepsilon_{T}\right)$ of TCP in the inherent presence of TRP to which Heisenberg's uncertainty principle is equally applicable. Consciousness will have to play its own role in quantum measurements; and they are thus liable to be governed by the uncertainty relations. The term "observation" is nothing but the utilization and involvement of the consciousness itself as indicated by $\mathrm{Pal}$ et al [2]. Mani Bhaumik [4] expressed, "In quantum physical experiments, an observer's consciousness is capable of bringing about a particular outcome from the coexisting possibilities inherent in any quantum system".

Pal et al [2] explained that the uncertainty or imprecision in the measured values is an inherent feature of the subatomic world. In our view, this subatomic world is controlled by the quantum mechanical activities of these TCP and TRP with which any matter as well as any mind is constituted. And the functional state of mind is consciousness which, in turn, plays the most prominent role in the quantum measurement. Thus the quantum measurement involving the role of consciousness is governed by these TCP, TRP, $\mathrm{T}_{\mathrm{F}}$ (micro), $\mathrm{T}_{\mathrm{F}}$ (macro), and the thought force $\left(\mathrm{T}_{\mathrm{F}}\right)$ in vitro and thought force $\left(\mathrm{T}_{\mathrm{F}}\right)$ in vivo. It is to be noted that these TCP and TRP function like wavicle: wave-particle duality.

Schrödinger [18a] expressed: "We cannot make any factual statement about a given natural object (or physical system) without 'getting in touch' with it. This 'touch' is a real physical interaction. Even if it consists only in our 'looking at the object' the latter must be hit by light-rays and reflect them into the eye, or into some instrument of observation. This means that the object is affected by our observation. You cannot obtain any knowledge about an object while leaving it strictly isolated. The theory goes on to assert that this disturbance is neither irrelevant nor completely survey-able. Thus after any number of painstaking observations the object is left in a state of which some features (the last observed) are known, but others (those interfered with by the last observation) are not 
known, or not accurately known. This state of affair is offered as an explanation why no complete, gap-less description of any physical object is ever possible".

As argued by many authors, "observation" itself plays a very important role in quantum measurements due to its interdependence with phenomena. The very act of "observation" distorts the state under 'observation' through the projection of TCP. The expected consequence is the "apparent" non-determinism in quantum measurements. The concept of "observation-phenomenon interdependence" is entirely governed by the quantum mechanical activities of these TCP in the presence of TRP. These TCP in the presence of TRP not only obey the uncertainty principle but also involve two different velocities (viz. V, the mechanical motion of the TCP and $\mathrm{u}$, the propagation of the associated wave when they are related by $\mathrm{u}=\mathrm{c}^{2} / \mathrm{V}$ ) present at a time.

\section{(xii) Brilliant Disguise: Light, Matter and the 'Zero-Point Field' Signify the Existence of TF (micro) and TF (Macro)}

Haisch et al [19] published the brilliant concept of 'ZeroPoint Field'. He expressed the concept of the existence of a background sea of light known as the electromagnetic zeropoint field of the quantum vacuum. Since zero-point field is everywhere, inside and outside of us, permeating every atom in our bodies, we are effectively blind to it. It blinds us to its presence. The world of light that we do see is all the rest of the light that is over and above the zero-point field. The probability of the existence of this 'background sea of quantum light filling the universe' through the 'ZeroPoint Field' signifies the existence of $T_{F}$ (micro) and $T_{F}$ (macro) due to the existence of the quantum mechanical activities of these TCP in the presence of TRP.

\section{(xiii) TCP, TRP and TF (Micro) may Play the most Significant Role in the Generation of Higgs Boson}

Every object as well as every mind has been treated here as being constituted by these TCP and TRP in the presence of TF (Micro). Thus the quarks and leptons are conceived here to be ultimately constituted by these TCP and TRP in the inherent presence of $\mathrm{T}_{\mathrm{F}}$ (micro).

The interactions between quarks and leptons cannot be mediated by themselves. The transitions between quark and lepton groups would be mediated by new force particles as indicated by Chris Quigg [20] and these transitions are thought to be mediated through Higgs boson. The transitions between quark and lepton groups could be mediated by the TCP in the presence of TRP. In this context, it may be mentioned what Chris Quigg [20] pointed out, "The Higgs boson is also held to be responsible for the fact that quarks and leptons within the same family have different masses. At very high energies all quarks and leptons are thought to be massless; at lower energies interactions with the Higgs particle confer on the quarks and leptons their varying masses. It has been proposed that the Higgs boson is not an elementary particle at all but rather a composite object made up of elementary constituents analogous to quarks and leptons but subject to a new kind of 'strong interaction', often called "technicolor", which would confine them within about $10^{-17}$ $\mathrm{cm}$. The phenomenon that would reveal such an interaction would become apparent at energies of about $1 \mathrm{TeV}$."

At this juncture it is provocative to note that there is a possibility of the generation of Higgs bosons through the strong interaction of TCP in the presence of TRP. This "extra strong interaction" which is often called "technicolor" is the $\mathrm{T}_{\mathrm{F}}$ (micro) itself in the region of $10^{-18}$ $\mathrm{cm}$. It is plausible to note here that the theoretically calculated radius of a TCP or TRP within a nucleon is $8.28 \times 10^{-18} \mathrm{~cm}$ and that within an electron is $2.113 \times 10^{-16} \mathrm{~cm}$. And it is also plausible here to indicate that the theoretically calculated energy level of the manifestation of $\mathrm{T}_{\mathrm{F}}$ (micro) is found to be $37.32 \times 10^{3} \mathrm{GeV}$ that is very close to $1 \mathrm{TeV}$ as indicated by Chris Quigg [20]. Thus, the generation of Higgs boson through the strongest interaction called "technicolor" is nothing but the $\mathrm{T}_{\mathrm{F}}$ (micro) itself caused by the TCP in the presence of TRP.

\section{(xiv) The Usual Decrease in the Value of Specific Heat of a Solid with the Lowering of Temperature Signifies the Vibrant Activity of TCP and TRP}

The usual decrease in the value of specific heat of a solid with the lowering of temperature can also be tackled by accepting the existence of $\mathrm{T}_{\mathrm{F}}$ (micro) along with the vibrant energy of these TCP and TRP with which the solid is assumed to be ultimately composed. The atomic heat which is the product of atomic weight and specific heat of a solid may be found to be maintained by $5.4122 \times 10^{23}$ TCP or TRP which, in turn, are equivalent to 6.4 calories as detected by Dulong and Petit. The lowering of temperature of a solid signifies the lowering of vibration of TCP and TRP with which it is ultimately constituted. Thus when there is a reduction in temperature, there is a simultaneous reduction in the inherent vibrant energy of TCP or TRP responsible for maintaining the normal atomic heat. That is why there is a decrease in the value of specific heat of a solid when the temperature of the solid is reduced.

Since the temperature of an atom is an outcome of its motion, atoms in a "BEC (Bose-Einstein Condensate) state" would lose their individual identities and behave as if they were a single "super-atom". The BEC, essentially, is a new state of matter, called the fifth state. This condensate is composed of TCP and TRP and these are thought to be the building blocks of mental life indicated by Pal et al [2].

\section{(xv). The physical world is nothing but a projection of the mind consisting of TCP and TRP that, in turn, are the ultimate constituents of any matter Also}

Pal et al $[1,3]$ explained that the universe exists along with the universal consciousness. This universal consciousness is a functional state of the Universal Mind (UM). This UM is constituted by these TCP and TRP which, in turn, are the ultimate constituents of any matter as well as any mind in the inherent presence of thought force $\left(\mathrm{T}_{\mathrm{F}}\right)$ in vitro and thought force $\left(\mathrm{T}_{\mathrm{F}}\right)$ in vivo. It is to be noted that these TCP and TRP are the ultimate constituents of any matter in the 
inherent presence of thought force $\left(\mathrm{T}_{\mathrm{F}}\right)$ in vitro. And these TCP and TRP are the ultimate constituents of any mind in the inherent presence of thought force $\left(\mathrm{T}_{\mathrm{F}}\right)$ in vivo.

Bhaumik [4] pointed out, "We must conclude, with Bishop Berkeley, that the physical world is nothing but a projection of the mind. 'I' and the universe somehow participate with one another. Mind affects matter and matter affects mind. Could the answer to the "why" of consciousness lie in John Wheeler's time-bending notion that our "observership brings the universe into being"?

John A. Wheeler clearly indicated that the process of recognizing an observable object is really a type of participation on the part of the observer for a specific object to be observed. This process of recognizing an observable object is possible through the projection of mind of the observer in the presence of his / her consciousness. I will never recognize any external object in the absence of the function of my mind (= consciousness).

This mind (with the help of TCP and TRP), in turn, exerts its functions through the brain with other parts of nervous systems (CNS, PNS along with ANS) in the biological systems in order to grasp this physical universe, of course, in the inherent presence of consciousness. And this mind is the finer instrument through which the Soul

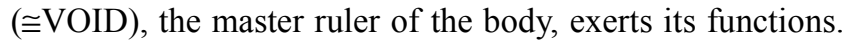
Thus, both the external something and the internal Soul

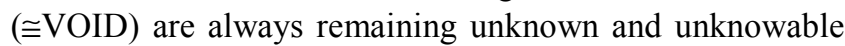
throughout. Their presence can be visualized only in the presence of the function of mind generating consciousness. So, there is always a bridge between the internal world and the external world through the vehicle of the mind (i.e. composed of TCP and TRP) in the presence of consciousness. All forms are only the external expressions of the thoughts projected by the mind. If we can sincerely hold on to a specific thought and project it outside, we can logically create a specific form, although this conclusion is apparently debatable.

Pal et al $[2,3]$ explained that any matter (as well as mind) being ultimately composed of these TCP and TRP should have some sort of 'mind' as Dyson indicated.

Bhaumik [4] also mentioned, "American psychologist William James stated, "there is only one primal 'stuff' of which everything is composed. David Bohm and Basil Hiley said that at some level of reality (in the pre-space / implicate order), mind and matter merge. Bhom maintained that implicit in the quantum potential was a "mind-like quality in matter," which he identified with the notion of active information. Even an electron, he argues, has a rudimentary "mental" aspect. If this is true, it's reasonable to ask whether our brains, as material outgrowths of this process, have evolved to operate in perfect resonance with this active information. "One could say," Bohm and Hiley allow, "that through the human being, the universe is making a mirror to observe itself."

Freeman J. Dyson expressed: "It appears that mind, as manifested by the capacity to make choices, is to some extent inherent in every atom. The second level is our direct human experience of our own consciousness. The third level is the entire universe. The universe as a whole is also weird, with laws of nature that make it hospitable to the growth of mind". Thus any matter (as well as 'mind') being ultimately composed of these TCP and TRP should have some sort of 'mind' as Dyson and Bhom indicated.

\section{(xvi) TCP and TRP Play Significant Roles in the Field of Cognitive Neuro-Science}

Pal et al [2] and Pal [21] showed that these TCP and TRP in the presence of thought force $\left(\mathrm{T}_{\mathrm{F}}\right)$ in vitro and thought force $\left(\mathrm{T}_{\mathrm{F}}\right)$ in vivo play significant roles in the field of cognitive neuro-science.

The mind of animate must create the wave towards any sensation in order to perceive it. In every phenomenon in nature we contribute at least half share and the nature brings half as indicated by Vivekananda [22]. If our half share is taken off, the thing must stop to exist for us. Nobody knows what is external; when we try to know it, it has to become that material which we furnish by projecting the mind (consisting of TCP and TRP) in the presence of consciousness. The reflections formed in the physical eye (through stimuli) only serve to call the attention of the conscious mind to the objects of its perception. Perception is a faculty by which mind learns to know what is going on within itself. To see a thing is to perceive the existence of its appearance within one's own mind. To see a thing is identical with touching it with the mind. The individual mind of a man being one with the Universal mind extends through space; and the things themselves that exist within the periphery of our mind can be perceived through the consciousness, the apparent center of which is generally thought to be located in the brain. If the mind touches an object through the quantum mechanical activities of these TCP and TRP, the impressions have to travel all the way to the brain. What we know of the external is as it is moulded, formed, fashioned by our own mind, which, in turn, exerts its actions through the brain.

The reigning tenet of quantum mechanics is the uncertainty principle. A consequence of the uncertainty principle is that the presence of an observer or experimenter determines the outcome of the observation or experiment. Simply stated, this means there is no objective reality; you 'create' what you see through the quantum mechanical activities of these TCP and TRP in the presence of consciousness. The quantized energy $\left(\varepsilon_{T}\right)$ of TCP represents universal consciousness. The individual consciousness owes its origin to the universal consciousness created by the same $\varepsilon_{T}$. Pal et al $[1,3]$ explained that these TCP and TRP are the ultimate constituents of any matter as well as any mind in the inherent presence of thought force $\left(\mathrm{T}_{\mathrm{F}}\right)$ in vitro and the thought force $\left(\mathrm{T}_{\mathrm{F}}\right)$ in vivo.

It is to be noted that TCP cannot exist without TRP and vice versa. These TCP and TRP function like wavicle: wave-particle duality. Both the TCP and TRP are interchangeable in the presence of consciousness, of course, in the inherent presence of the Soul ( $\cong$ Void which is the source of infinite energy) to complete the process of observation in order to see the observable 'object'. 
There is 'something' which is outside, which is only the occasion, the suggestion; and upon that 'suggestion' I project the TCP of my mind with the help of consciousness to see (identify) this external 'suggestive something'.

What is the process of observation? How do we see? It is to be noted that these TCP and TRP are interchangeable in the presence of consciousness to complete the process of observation in order to see the observable 'object'. When I project the TCP of my mind with the help of consciousness to see the external observable 'object', this TCP from my mind is converted into TRP in the presence of my consciousness. This TRP cannot exist without TCP. These TRP and TCP thus 'create' the observable object that I see.

TCP from this observable 'object' is to be returned to me in order to complete the process of observation for seeing the observable 'object'. This returned TCP from the object is to be converted into TRP in the presence of my consciousness and this converted TRP is to be retained and stored within my mind for future use. This conversion of TCP from the observable 'object' into TRP within my mind is necessary for forming an impression of the object within my mind so that I can retain that image with the help of TRP within my mind for future 'recognition' when I would come across the same 'thing'. This is possible through the power of the Soul ( $\cong$ Void which is the source of infinite energy) in the presence of consciousness.

It is to be noted that these TCP and TRP are the ultimate constituents of any matter as well as any mind in the inherent presence of thought force $\left(\mathrm{T}_{\mathrm{F}}\right)$ in vitro and the thought force $\left(\mathrm{T}_{\mathrm{F}}\right)$ in vivo. It is to be understood that when we try to see an observable external 'object', it has to become that material which we furnish by projecting the mind (consisting of TCP and TRP) in the presence of consciousness and it takes the form that I see.

Thus, there is no objective reality; I 'create' what I see through the quantum mechanical activities of these TCP and TRP in the presence of my consciousness. These TCP and TRP are interchangeable in the presence of consciousness to 'create' and then see the observable 'object'. "Matter is an expression of mind, not separate from mind, but mind manifested materially".

Consciousness, not matter, is the ground of all existence, declares University of Oregon physicist Goswami through his published (1993) book, "The Self-Aware Universe: How Consciousness Creates the Material World". He accepts the Vedantic view and holds that the universe is self-aware, and that consciousness creates the physical world. Matter is an expression of mind, not separate from mind, but mind manifested materially.

John Wheeler strongly believed that "in defining any useful concept of reality" we have to take into account "the indispensable place of the participating observer--evidenced in quantum mechanics" as indicated by Bhaumik [4]. Wheeler has speculated that reality is created by observers in the universe. His time-bending notion is that our "observership brings the universe into being".

Wheeler indicated that the process of recognizing an observable object is really a type of participation on the part of the observer for a specific object to be observed.
This process of recognizing an observable object is possible through the projection of mind of the observer in the presence of his / her consciousness.

How could an object's existence depend upon the act of observation? This is due to the fact that an object's existence as well as the act of observation through the prevailing consciousness is totally dependent on the existence of the quantum mechanical activities of these TCP and TRP in the presence of consciousness. The quantized energy $\left(\varepsilon_{T}\right)$ of TCP represents universal consciousness. The individual consciousness owes its origin to the universal consciousness created by the same $\varepsilon_{T}$. Pal et al $[1,3]$ explained that these TCP and TRP are the ultimate constituents of any matter as well as any mind in the inherent presence of thought force $\left(\mathrm{T}_{\mathrm{F}}\right)$ in vitro and the thought force $\left(\mathrm{T}_{\mathrm{F}}\right)$ in vivo.

How do we all see the same things? Because we all have similar parts (i.e. TCP and TRP) of the Universal Mind that, in turn, is constituted by these TCP and TRP. Those who have like minds will see like things, and those who have not, will not see alike. I will never know that external 'something' in the absence of the function of my mind ( $\cong$

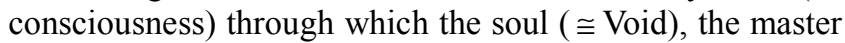
ruler of the living body, exerts its functions. Thus both the external something and the internal Soul are always remaining unknown and unknowable throughout. Their presence can be visualized only in the presence of the function of mind generating consciousness. So, there is always a bridge between the internal world and the external world through the vehicle of mind (composed these TCP and TRP) in the presence of consciousness.

In our view, the brain is only a fine "instrument" through which the mind exerts its functions with the help of TCP and TRP. The "binding problem" associated with the concepts of coherence can also be tackled through the quantum mechanical activities of these TCP and TRP. A single unified experience of an object having different

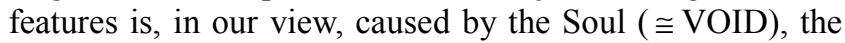
master ruler of the body. And this Soul, with the help of consciousness, exerts its functions through the finer instrument called "mind". Being guided by the Soul, the mind can, with the help of TCP and TRP, correlate and assemble all the different stimuli (relating to the different features of an object) into a unified experience of a single thing through the utilization of the instrumental brain. The "science of observation" in the field of "cognitive neuroscience" can be explained through the existence and function of Soul and mind in the inherent presence of consciousness.

\section{(xvii) Controlling Movement through thought Alone Signifies the Positive Proof for Existence of the thought Force $\left(T_{F}\right)$ in Vivo}

Pal [5] showed that Thought force $\left(\mathrm{T}_{\mathrm{F}}\right)$, an expression of the universal consciousness, is the primordial quantum field that, in turn, functions as the primary unified field. $\mathrm{T}_{\mathrm{F}}$ itself may thus be found to be the original single primary unified field that is the origin of all the four fundamental fields 
along with both the $\mathrm{T}_{\mathrm{F}}$ (micro) and $\mathrm{T}_{\mathrm{F}}$ (macro). This $\mathrm{T}_{\mathrm{F}}$ being an expression of the universal consciousness is applicable to any inanimate object as well as to any biological system (having thinking ability). Thus the $\mathrm{T}_{\mathrm{F}}$ being an expression of the quantized energy $\left(\varepsilon_{T}\right)$ of TCP exerts its functions both in vitro and in vivo (see Scheme-II).

In a purpose to involve both the non-living and living systems of the world, Pal [5] has shown the existences of these TCP, TRP and thought force $\left(\mathrm{T}_{\mathrm{F}}\right)$ in vitro and thought force $\left(\mathrm{T}_{\mathrm{F}}\right)$ in vivo.

The non-living system of the world is governed by the thought force $\left(\mathrm{T}_{\mathrm{F}}\right)$ in vitro and this

Thought force $\left(\mathrm{T}_{\mathrm{F}}\right)$ in vitro gives rise to $\mathrm{T}_{\mathrm{F}}$ (micro), $\mathrm{SNF}$, EMF, WNF, GF and $\mathrm{T}_{\mathrm{F}}$ (macro)

where $\mathrm{T}_{\mathrm{F}}$ (micro) $=$ Thought force in microcosm, $\mathrm{SNF}=$ Strong nuclear force, $\mathrm{EMF}=$ Electromagnetic force, $\mathrm{WNF}=$ Weak nuclear force, $\mathrm{GF}=$ Gravitational force and $\mathrm{T}_{\mathrm{F}}$ (macro) $=$ Thought force in macrocosm. It is to be noted here that $\mathrm{T}_{\mathrm{F}}$ (micro) is a stronger force than the SNF and $\mathrm{T}_{\mathrm{F}}$ (macro) is a weaker force even than the GF.

The living system of the world is governed by the thought force $\left(\mathrm{T}_{\mathrm{F}}\right)$ in vivo and this

Thought force $\left(\mathrm{T}_{\mathrm{F}}\right)$ in vivo is a type of force that represents the biological 'thought' which is the action of mind. This 'thought' being a type of force controls the 'thought processes' involving the firing of neurons through the quantum mechanical activities of these TCP and TRP in the presence of consciousness. Consciousness in living organisms is a process which involves the quantum mechanical activities of these TCP and TRP, the ultimate constituents of any matter as well as any mind in the inherent presence of thought force $\left(\mathrm{T}_{\mathrm{F}}\right)$ in vitro and the thought force $\left(\mathrm{T}_{\mathrm{F}}\right)$ in vivo as indicated by Pal et al [3]. These TCP and TRP govern the activities of neurons (not the other way round). Neurons are simply the equipments used to generate consciousness and awareness. This consciousness, in turn, is the quantized energy $\left(\varepsilon_{T}\right)$ of TCP.

Thought force $\left(\mathrm{T}_{\mathrm{F}}\right)$ being the primordial quantum field functions as the original single primary unified field that is not only the origin of all the four fundamental fields along with both the $\mathrm{T}_{\mathrm{F}}$ (micro) and $\mathrm{T}_{\mathrm{F}}$ (macro) but also the origin of Thought force $\left(\mathrm{T}_{\mathrm{F}}\right)$ in vivo (see Scheme-II).

The thought force $\left(\mathrm{T}_{\mathrm{F}}\right)$ in vivo is demonstrated in numerous experiments in which thought has an effect on a physical process (often known as mind over matter). This biological 'thought' is a type of force that can cause movement. Controlling movement through thought alone is observed in several experiments conducted by Birbaumer [23], Donoghue et al [24-27], Hatsopoulos [28] and Miguel [29]. These experiments thus signify the existence of thought force $\left(\mathrm{T}_{\mathrm{F}}\right)$ in vivo.

\section{(xviii) TCP and TRP Play Prominent Roles in the Exercise of Paranormal Power Like Extra Sensory Perception (ESP) and Psychokinesis (PK)}

Paranormal power has broadly been classified into (a) Extra sensory perception (ESP) and (b) Psychokinesis (PK) which was previously called Telekinesis. Parapsychologists have explained ESP as receiving information beyond the five measurable senses though it is considered by some people to exist in the realm of metaphysics or something impracticably real. ESP is classified into telepathy, clairvoyance and precognition. Telepathy is the communication between minds through unknown channel. Telepathy involves exchanging thoughts, imaginary and emotions between minds other than physical channels.

TCP and TRP being the ultimate constituents of any matter as well as any mind play the most significant roles in the ESP and 'psychokinesis' (PK). Quantum physics has discovered a seamless fabric of intertwining threads of energy. We live in an unimaginable ocean of waves and frequencies of TCP and TRP that are the true cause for the functional existence of the paranormal power.

Bhaumik [4] pointed out, "Sheldrake has advanced the notion of an "extended mind" that can "reach out" to influence things well beyond the brain's boundaries. Like Nobel physicist Brian Josephson, he is deeply interested in finding a scientific explanation of psi phenomenon such as telepathy. A convincing proof of such phenomenon will obviously demonstrate that consciousness is not merely confined within the skull; it is capable of biological nonlocality. Mind is entangled with matter as matter is entangled with mind."

\section{(xix) TCP and TRP Play Prominent Roles in Information Processing}

Pal [30] showed that the quantum mechanical activities of TCP and TRP in the inherent presence of the thought force $\left(\mathrm{T}_{\mathrm{F}}\right)$ in vitro and thought force $\left(\mathrm{T}_{\mathrm{F}}\right)$ in vivo play significant roles in information processing. These TCP and TRP are inter-convertible in the presence of consciousness to carry and retain a specific "thought" and also for its communication from one person to another in the presence of the thought force $\left(\mathrm{T}_{\mathrm{F}}\right)$ in vitro and thought force $\left(\mathrm{T}_{\mathrm{F}}\right)$ in vivo.

Davies [31] expressed that life's distinctiveness does not lie in its chemical properties but in its "informational properties". A living organism is a complex information processing system. Pal [30] showed that the universal consciousness is a functional state of the UM which is constituted by these TCP and TRP which, in turn, are the ultimate constituents of any matter as well as any mind. This UM along with the universal consciousness is thus responsible for the manifestation of this Universe with all of its inhabitants. As this UM manifests its own inherent characteristics through the generations of each and all individual minds in a purpose to realize the "reality" of the universe itself, so the biogenesis may be thought to be predetermined. A living organism is thus a complex information processing system and the information is coming from the UM through TCP and TRP.

Davies [31] in his 'The Fifth Miracle', concluded, "I am of the opinion that there remains a huge gulf in our understanding. It is not merely ignorance about certain technical details; it is a major conceptual lacuna-----we are missing something very fundamental about the whole 
business---a fully satisfactory theory of the origin of life demands some radically new ideas".

Our consciousness model involving TCP, TRP and thought force $\left(\mathrm{T}_{\mathrm{F}}\right)$ in vitro and thought force $\left(\mathrm{T}_{\mathrm{F}}\right)$ in vivo provides a simple and radically new idea to explain the evolution of universe along with life and consciousness where $\varepsilon_{T}$, the quantized energy of TCP represents universal consciousness.

\section{(xx) TCP and TRP play prominent roles to form a possible gross bridge between mind and matter:}

Pal et al [3] showed that these TCP and TRP are the ultimate constituents of any matter as well as any mind in the presence of thought force $\left(\mathrm{T}_{\mathrm{F}}\right)$ in vitro and thought force $\left(\mathrm{T}_{\mathrm{F}}\right)$ in vivo. It is to be noted that these TCP and TRP are the ultimate constituents of any matter in the inherent presence of thought force $\left(\mathrm{T}_{\mathrm{F}}\right)$ in vitro. And these TCP and TRP are the ultimate constituents of any mind in the inherent presence of thought force $\left(\mathrm{T}_{\mathrm{F}}\right)$ in vivo.

Pal [32] explained mental processes involving consciousness through the consciousness model incorporating quantum mechanical activities of TCP and TRP in the presence of Thought force $\left(\mathrm{T}_{\mathrm{F}}\right)$ in vitro and Thought force $\left(\mathrm{T}_{\mathrm{F}}\right)$ in vivo.

Georgiev [33] explained through experimental observation that our mind operates at $100 \mathrm{GHz}$ (dynamical timescale of 10 picoseconds). It is found that the calculated frequency of TCP is $75 \mathrm{GHz}$ that is close to $100 \mathrm{GHz}$. And the calculated time period of the TCP $=1.33 \times 10^{-11} \mathrm{sec}$ that is equivalent to 10 picoseconds $=10^{-11} \mathrm{sec}$.

It appears that there is a significant relationship between the operational mind and the quantum mechanical activities of these TCP and TRP. In this way, the mind is a state created by these TCP and TRP. Or the mind is constituted and operated by these TCP and TRP. These TCP and TRP can thus form a possible bridge between the mind and matter in the presence of thought force $\left(\mathrm{T}_{\mathrm{F}}\right)$ in vitro and thought force $\left(\mathrm{T}_{\mathrm{F}}\right)$ in vivo.

\section{Discussions and Conclusion}

\subsection{Discussions}

The consciousness model incorporating TCP, TRP and thought force $\left(\mathrm{T}_{\mathrm{F}}\right)$ in vitro and thought force $\left(\mathrm{T}_{\mathrm{F}}\right)$ in vivo can provide plausible guidelines to:

(i) understand the origin of matter and force

(ii) form a possible gross bridge between the classical physics and quantum physics through consciousness ( $=\mathcal{E}_{T}$, the quantized energy of TCP)

(iii) identify the primordial quantum field $=$ a single super-force that dominated the first instants of creation. This mysterious super-force is the Thought force (TF) itself. Physicists determined that underlying quantum fields give birth to elementary particles. Thought force (TF) being the primordial quantum field gives birth to TRP that appears to be the origin of all the matter particles. TCP is the carrier of thought force (TF) that, in turn, appears to be the origin of all the fields. TCP is thus the origin of all the field particles (see Scheme-I). TCP cannot exist without TRP and vice versa.

(iv) form a possible gross bridge between mind and matter

(v) form a possible gross bridge between present physics and cognitive science

(vi) form a possible gross bridge between psychology and natural sciences

(vii) show mathematically that the cosmic microwave background radiation (CMBR) temperature is due to the quantized energy $\left(\varepsilon_{T}\right)$ of the TCP in the inherent presence of TRP. It is expressed that the CMBR temperature exists due to the existence of

$\mathcal{E}_{T}$ of TCP radiated from the radiant mass of universe. The existence of the CMBR temperature confirms the existence of TCP in the inherent presence of TRP. The existence of TCP ensures the existence of thought force (TF). This TF being an expression of the universal consciousness is applicable to any inanimate object as well as to any biological system (having thinking ability). Thus the TF being an expression of the quantized energy $\left(\mathcal{E}_{T}\right)$ of TCP exerts its functions both in vitro and in vivo (see Scheme-II)

(viii) explain that the non-living system of the world is governed by the thought force (TF) in vitro and this Thought force (TF) in vitro gives rise to TF (micro), SNF, EMF, WNF, GF and TF (macro) where TF $($ micro $)=$ Thought force in microcosm, SNF = Strong nuclear force, EMF = Electromagnetic force, $\mathrm{WNF}=$ Weak nuclear force, GF = Gravitational force and TF (macro) = Thought force in macrocosm. It is to be noted here that TF (micro) is a stronger force than the SNF and TF (macro) is a weaker force even than the GF

(ix) explain that the thought force (TF) in vivo is demonstrated in numerous experiments in which thought has an effect on a physical process (often known as mind over matter)

(x) explain non-locality problem in quantum physics. Everything in this universe is interlinked and intertwined through the existence of the quantum mechanical activities of these TCP in the presence

of TRP. The $\varepsilon_{T}$, the quantized energy of TCP represents universal consciousness. This universal consciousness functions as a universe wide web (uww) covering the universe as a whole with all its parameters (including void) and inhabitants (with or without consciousness). In this picture, uww of consciousness, quantum concepts like wave particle dualism, position momentum uncertainty, nonlocality and concept of unified field become somewhat understandable as all the entities of this universe are interlinked and intertwined. In this 
picture, the universal consciousness replaces ether of yesteryears and contains the whole of the universe in its fold.

(xi) interpret the 'spooky action-at-a-distance' that is built in nature through the existence of these TCP and TRP in the presence of thought force (TF). These TCP and TRP are the ultimate constituents of any matter as well as any mind. The spooky nonlocal correlations-at-a-distance might evidence a Holy Ghost at work through the existence of the quantum mechanical activities of these TCP and TRP in the inherent presence of Thought force (TF) in vitro and Thought force (TF) in vivo.

(xii) explain that quantum fields signify the existence of $\mathrm{TF}$ (micro) (= Thought force in microcosm and TF (macro) (= Thought force in macrocosm): Thought force (TF) is bridging the microcosm and macrocosm through the generation of a universal web of quantum fields of $\mathrm{TF}$ (micro) and $\mathrm{TF}$ (macro).

(xiii) explain the functional paranormal power like the Extra Sensory Perception (ESP) and Psychokinesis (PK). The existence of ESP and PK significantly indicates the functional existence of these TCP and TRP in the inherent presence of thought force (TF) in vitro and the thought force (TF) in vivo. These TCP, TRP and the thought force (TF) in vitro and thought force (TF) in vivo can exert their roles mentally (internally) as well as physically (externally).

(xiv) understand relationship among consciousness, mind, brain and matter

(xv) interpret what is life in gross mathematical sense. Pal [18] expressed:

$$
\begin{aligned}
& \text { Life }=\mathrm{f}(\text { Consciousness })=\mathrm{f}\left(\mathcal{E}_{T}\right) \\
& \text { where } \varepsilon_{T}=\text { quantized energy of the } \\
& \text { TCP }=4.384 \times 10^{-16} \mathrm{erg}
\end{aligned}
$$

These concrete predictions through the proposed consciousness model for providing plausible guidelines are elaborately expressed, although they are new to the scientific world. The existence of these TCP, TRP and the thought force $\left(\mathrm{T}_{\mathrm{F}}\right)$ in vitro and thought force $\left(\mathrm{T}_{\mathrm{F}}\right)$ in vivo and their significant roles are absolutely necessary to provide plausible guidelines.

The existence of TCP, TRP and thought force $\left(\mathrm{T}_{\mathrm{F}}\right)$ in vitro and thought force $\left(\mathrm{T}_{\mathrm{F}}\right)$ in vivo may provide plausible guidelines to lucidly explain the evolution of universe with laws of natural science like physics, chemistry and biology (with consciousness).

It appears that the standard model of physics is to be correctly tuned by ascertaining the constituents of quarks and leptons in the presence of unified field in order to form a possible gross bridge between mind and matter, present physics and cognitive science, psychology and natural sciences, classical physics and quantum physics.

\subsection{Conclusion}

All these specific theoretical aspects signify, justify and support the existence of TCP, TRP, thought force $\left(\mathrm{T}_{\mathrm{F}}\right)$, thought force $\left(\mathrm{T}_{\mathrm{F}}\right)$ in vitro and thought force $\left(\mathrm{T}_{\mathrm{F}}\right)$ in vivo along with the $\mathrm{T}_{\mathrm{F}}$ (micro) and $\mathrm{T}_{\mathrm{F}}$ (macro).

\section{References}

[1] D. Pal and A.U. De, Physics of consciousness and its model may provide guidelines to solve Many scientific problems. Neuroquantology 1: 17-28(2004)

[2] D. Pal and A.U. De, Consciousness model: Significance of thought-carrying particles and thought-retaining particles in quantum measurement as well as cognitive problem. Neuroquantology 2: 115-116 (2005)

[3] D. Pal and A.U. De, The cosmic microwave background radiation temperature signifying the existence of the thought-carrying particle, thought retaining particle and thought force. NeuroQuantology 10: Issue3; 428-442 (September 2012)

[4] M. Bhaumik, Code Name GOD. (Penguin Books India Pvt. Ltd., 11 Community Centre, Panchsheel Park, New Delhi 110017 , India) pp. 132-133; 161-162; 167; 171; 177; 183 and 184. 185-186; 89-190; 198 (2006)

[5] D. Pal, Existence of thought force and its characteristics. Communicated to American Journal of Modern Physics (AJMP) (2013)

[6] V. F. Weisskopf, The Origin of the Universe, The World of Physics, (Simon and Schuster, 1230 Avenue of Americas, New York 10020) 3, pp. 10 and 314 (1987)

[7] DJ. Fixsen, THE TEMPERATURE OF THE COSMIC MICROWAVE BACKGROUND. The Astrophysical Journal 707: 916 (2009)

[8] F. Wilczek, Mass Without Mass I: Most of matter. Physics Today 11 (November, 1999)

[9] R. Nelson, Director, Global Consciousness Project, Princeton, New Jersey. (2009) rdnelson@princeton.edu

[10] D. Radin, The Conscious Universe: The Scientific Truth of Psychic Phenomena. (Harper Edge) (1997) ISBN 0-06251502-0.

[11] R. Penrose, Shadows of the Mind: A Search for the Missing Science of Consciousness. (Oxford University Press) (1994)

[12] W. Van De Bogart, Earth portals: Exploring New Metaphors of Consciousness 1993 willard@earthportals.com

[13] Eds. B. Jezowska-Trzebiatowska, B,Kochel J. Slawinski and W. Strek, Photon Emission from Biological Systems, World Scientific, Singapore. 1987.

[14] Eds. FA. Popp., Li KH. and Gu Q. Recent Advances in Biophoton Research and its Applications, World Scientific, Singapore. 1992.

[15] FA.Popp, In recent Advances in Biophoton Research and its Applications, eds. FA Popp et al, World Scientific, Singapore, 1992; 1-16. 
[16] MR. Wehr, Richards JA. Jr and Adair T W. Physics of the Atom, Narosa Publishing House, 6, Community Centre, Panchseel Park, New Dilhi 110017; Fourth Edn.; 224- 225 and 519 (1996)

[17] HJ.Maris, On the fission of elementary particles and the evidence for fractional electrons in liquid helium. Journal of Low Temperature Physics 2000; 120: 173-204.

[18] D. Pal, Possible bridging the classical physics and quantum physics through consciousness. Communicated to American Journal of Modern Physics (AJMP) (2013)

[18a] E. Schrödinger, What Is Life? With Mind and Matter, First published in 1944. (Cambridge University Press) 125-127 (1967)

[19] B.Haisch, A.Rueda and H.Puthoff, Inertia as a zero-pointfield Lorentz force; Physical Review A 1994; 49: 678

[20] Chris. Quigg. Elementary Particles and Forces, The World of Physics, Simon and Schuster, 1230 Avenue of Americas, New York 10020. 1987; Vol. II: 885 - 891.

[21] D. Pal, Role of though-carrying particle (TCP), thought retaining particle (TRP) and thought force (TF) in vitro and thought force (TF) in vivo of the developed consciousness model in quantum measurement as well as cognitive problem. Communicated to American Journal of Modern Physics (AJMP) (2013)

[22] Vivekananda "Meditation", "The complete works of Swami Vivekananda, Advaita Ashrama, 5, Dehi Entally Road Cal7000014, 1stedn.; 1989; Vol-4:229; "Vedanta", ibid; Vol3:403-404; COSMOLOGY, ibid.; Vol-2:441.

[23] N.Birbaumer, N.Ghanayim, T.Hinterberger, I. Iversen., B. Kotchoubey, A.Kübler, J.Perelmouter, E. Taub, and H. Flor. A spelling device for the paralysed, Nature 398, March 1999; Number 6725: 297-9825.

[24] PJ.Donoghue, D. Mijail, GN. Serruya, LP. Hatsopoulos, FR. Matthew. Brain-machine interface: Instant neural control of a movement signal, Nature 416, 14 March 2002; Number 6877: 141.

[25] LR. Hochberg, MD. Serruya, GM. Friehs, JA. Mukand., M.
Saleh, AH. Caplan, A. Branner, D.Chen, RD. Penn and JP. Donoghue. Neuronal ensemble control of Prosthetic Devices by a human with tetraplegia, Nature, 422, 13 July 2000; 164- 171 .

[26] RK. Aaron, HM. Herr, D McK. Ciombor, LR. Hochberg, JP. Donoghue, CL.Briant, JR. Morgan, and MG.Ehrlich. Horizons in prosthesis development for restoration of Limb Function. J.Am. Accad Ortho Surg September 2006; 14 (10): S198-S204.

[27] JP. Donoghue. Connecting cortex to machines: recent advances in brain interfaces, Nature Neuroscience Supplement, November 2002; 5: 1085-8.

[28] D. Rubino, KA. Robbins, and MG. Hatsopoulos. Propagating waves Mediate information transfer in the motor cortex, Nature Neuroscience.19 November 2006; 9:1549-1557.

[29] Miguel MAL. Nicolelis. Brain-Machine interfaces to restore motor function and probe neural circuits, Nature Reviews Neuroscience 2003; 4: 417-422.

[30] D. Pal, Interpretation of information processing and mode of perception through the consciousness model involving though-carrying particle (TCP), thought retaining particle (TRP) and thought force (TF) in vitro and thought force (TF) in vivo. Communicated to American Journal of Modern Physics (AJMP) (2013)

[31] P. Davies, The Fifth Miracle: The Search for the Origin and Meaning of Life. (Simon \& Schuster 1999)

[32] D. Pal, Explanation of mental processes involving consciousness through the consciousness model incorporating quantum mechanical activities of Thoughcarrying particle (TCP) and Thought retaining particle (TRP) in the presence of Thought force (TF) in vitro and Thought force (TF) in vivo. Communicated to American Journal of Modern Physics (AJMP) (2013)

[33] D. D. Georgiev, Consciousness operates beyond the timescale for discerning time intervals: implications for Qmind theories and analysis of quantum decoherence in brain. NeuroQuantology2:136and140-141(2004) 